\title{
Screening Oryza Species Plants for Rice Sheath Blight Resistance
}

\author{
G. C. Eizenga, Dale Bumpers National Rice Research Center, USDA-ARS, Stuttgart, AR 72160; F. N. Lee, Rice \\ Research and Extension Center, University of Arkansas, Stuttgart; and J. N. Rutger, Dale Bumpers National Rice \\ Research Center, USDA-ARS, Stuttgart
}

\begin{abstract}
Eizenga, G. C., Lee, F. N., and Rutger, J. N. 2002. Screening Oryza species plants for rice sheath blight resistance. Plant Dis. 86:808-812.

Rice wild relatives, Oryza species, are one possible source of sheath blight (Rhizoctonia solani) resistance genes. However, Oryza spp. cannot be screened in the field as is done for cultivated rice (O. sativa) because the plant canopy does not favor disease development and many plants drop mature seed. Thus, a growth chamber-greenhouse method of screening Oryza spp. and their early generation progeny is needed. Primary-secondary and ratoon tillers of rice cultivarsgermplasm which ranged from moderately resistant to very susceptible were evaluated first for sheath blight susceptibility. Plants were inoculated by placing $R$. solani-colonized toothpicks at the leaf collar, then incubating plants in a growth chamber. After 7 days, plants were visually rated for sheath blight severity, and the lesion length of each leaf was measured. Ranking of cultivar-germplasm susceptibility by visual rating of primary-secondary tillers corresponded to the ranking from field ratings. Visual ratings correlated best with combined lesion length of the second and third leaves. For ratoon tillers, visual ratings correlated best with second-leaf lesion length. Next, this method was used with ratoon tillers to evaluate sheath blight susceptibility of 21 Oryza spp. accessions and $\mathrm{F}_{1}$ progeny from crosses between 17 accessions and cultivated rice. This method proved useful on a limited scale for screening germplasm that could not be evaluated under field conditions.
\end{abstract}

Additional keywords: Thanatephorus cucumeris

Sheath blight of rice (Oryza sativa L.) is a major rice disease throughout the world including the southern United States. This disease, which is caused by Rhizoctonia solani Kühn (teleomorph: Thanatephorus cucumeris (Frank) Donk), was first reported in 1910 and now occurs throughout temperate and tropical production areas, being most prominent where rice is grown under intense, high-fertility production systems. Initial symptoms consist of lesions on the sheaths of lower leaves at late tillering or early internode elongation growth stages. Under favorable conditions of low sunlight, high humidity ( $\geq 5 \%$ ), and warm temperature $\left(28\right.$ to $\left.32^{\circ} \mathrm{C}\right)$, the infection spreads rapidly by means of runner hyphae to upper plant parts, including leaf blades and adjacent plants. Lesions may coalesce to encompass the entire leaf sheath and stem $(13,21)$.

The fungus affecting rice belongs to anastomosis group AG-1, intraspecific group I-A of $R$. solani (21). $R$. solani isolates used in screening for reaction to sheath

Corresponding author: Georgia C. Eizenga

E-mail: geizenga@spa.ars.usda.gov

Accepted for publication 26 March 2002.

Publication no. D-2002-0517-01R

This article is in the public domain and not copyrightable. It may be freely reprinted with customary crediting of the source. The American Phytopathological Society, 2002 blight are obtained from infected rice plants, and differences in virulence of $R$. solani isolates have been noted by measuring the lesion size, but no accepted system of differentiating the isolates pathogenic to rice has been reported to date (4). Molecular differences in isolates have been characterized using both restriction fragment length polymorphism (RFLP) (14) and polymerase chain reaction (PCR)based markers (20).

To date, only partial resistance to rice sheath blight has been identified, as evidenced by a survey of 6,000 rice cultivars from 40 countries from which no cultivar exhibiting a major gene for rice sheath blight resistance was identified (8). More recently, quantitative trait loci (QTL) analysis identified six QTLs associated with sheath blight resistance on 6 of the 12 rice chromosomes, but only one QTL appeared to be independent of plant height, a morphological trait associated with sheath blight resistance (14). Additional research suggests it is feasible to identify major genes conferring high levels of partial resistance (19), pyramid these genes, and achieve nearly complete sheath blight resistance.

Sheath blight resistance also was identified in the Oryza spp., O. minuta J.S. Presl. ex C.B. Presl. (1) and $O$. officinalis Wall ex Watt (12), and transferred into cultivated rice through backcrossing. These studies indicate Oryza spp. are an important source of sheath blight resistance genes, and transferring these genes into rice cultivars adapted to the production area in the southern United States is an important disease management strategy.

Most testing for sheath blight resistance is done in the field for rice breeding programs. Reported methods of evaluating rice sheath blight resistance are based on field ratings done at internode elongation or later, when the plants are in the reproductive growth stage (23). However, this is problematic for most wild relatives of rice (Oryza spp.) because these species often are considered weeds and some are noxious weeds in the United States (26). In addition, most wild Oryza spp. drop mature seed to the soil and may have an "open" growth habit or morphology not conducive to sheath blight infection under field conditions. Also, few progeny are obtained from crosses between cultivated rice and wild Oryza sp.; therefore ratoon tillers of individual plants need to be evaluated in early generations. Ratoon tillers, tillers which develop after the original tillers are cut off, are used so the panicle morphology can be observed and additional backcrosses can be made. For these reasons, evaluating the Oryza spp. and their early generation progeny is more practical in the growth chamber (or greenhouse).

The objectives of this study were to (i) determine how well sheath blight disease ratings from a growth chamber inoculation method compared with field ratings of southern rice cultivars using primary or secondary tillers and ratoon tillers and (ii) evaluate a growth chamber method for assessing sheath blight resistance using ratoon tillers of Oryza spp. and their $\mathrm{F}_{1}$ progeny from crosses with cultivated rice.

\section{MATERIALS AND METHODS}

Germplasm evaluated. Cultivars $\mathrm{Cy}$ press (16), Katy (18), Lacassine (15), Lebonnet (3), Leah (25), Maybelle (2), Mars (11), and the germplasm lines LSBR-5 and LSBR-33 (27) were evaluated in the field on a scale of 0 to 9 , where $0=$ no lesion development and $9=$ lesions covering flag leaf sheath and above with significant panicle death, and ranged in susceptibility from very susceptible to moderately resistant. Specifically (means and standard deviations in parentheses), Lacassine (6.75 $\pm 1.75)$ and Lebonnet $(7.21 \pm 1.37)$ were rated very susceptible; Cypress (5.73 \pm $1.48)$ and Maybelle $(6.23 \pm 1.47)$ rated susceptible; and Katy (4.75 \pm 0.71$)$, Leah 
$(5.25 \pm 0.96)$, and Mars (4.91 \pm 1.22$)$ were moderately susceptible (24; K. A. K. Moldenhauer, University of Arkansas, personal communication). The ratings for LSBR-5 (3.66 \pm 1.87$)$ and LSBR-33 (1.57 \pm 1.12 ) ranged from 1 to 3 , resistant to moderately resistant, in tests where a very susceptible variety such as Labelle rated 7 to 9 (27).

The 20 wild Oryza species reported as highly resistant to sheath blight, rated " 1 " based on field ratings conducted in the Philippines (9), and O. rufipogon Griff., (IRGC 100912 or PI 590420), which has been used as a source of stem rot resistance (6), were used in this study. The parental lines in the crosses with the Oryza spp. were RU9401188, a long grain experimental line (K. A. K. Moldenhauer, University of Arkansas), and Bengal, a medium grain cultivar (17). Both RU9401188 and Bengal were considered moderately susceptible to sheath blight with ratings from 5 to 7 in inoculated field nurseries (K. A. K. Moldenhauer, University of Arkansas, personal communication).

Isolates and inoculum production. Isolates of $R$. solani used in this study were collected from diseased rice plants in rice production fields identified in Arkansas. The isolates were grown on potato dextrose agar (PDA; Difco Laboratories, Detroit, MI) in petri dishes in a $28^{\circ} \mathrm{C}$ incubator. Isolates were stored and maintained as dried sclerotia in a $28^{\circ} \mathrm{C}$ incubator. $R$. solani isolates were maintained as sclerotia because the sclerotia are more stable than agar plugs and easier to store. Isolates also were stored on PDA slants in the refrigerator. The isolates, GRUBBS18A and LNG14A, were collected near Grubbs and Hazen, AR, respectively, in the early 1980s, and 95KBNT was collected near Stuttgart, AR, in 1995. Potato dextrose broth (Difco Laboratories) was prepared as recommended by the manufacturer, in a beaker twice the volume of the broth, covered with aluminum foil and autoclaved for $15 \mathrm{~min}$. Next, wood toothpicks (3 mm diameter) cut to approximately 2 -cm length including one tapered end were added to the sterile broth, allowed to infiltrate with broth for $30 \mathrm{~min}$, then the mixture of broth and toothpicks was autoclaved for $40 \mathrm{~min}$. A solution of PDA (Difco Laboratories) was prepared per manufacturer recommendations, then autoclaved for $15 \mathrm{~min}$. When the agar was cool to the touch, $0.5 \mathrm{ml}$ of tetracycline ( $0.8 \mathrm{~g}$ in $80 \%$ ethanol) per 100 $\mathrm{ml}$ of agar was added. Approximately 20 $\mathrm{ml}$ of sterile agar was poured into sterile petri dishes $(100 \times 15 \mathrm{~mm})$ and allowed to cool. Toothpick pieces were placed on the agar simultaneously with sclerotia of $R$. solani isolates. These petri dishes were incubated at $28^{\circ} \mathrm{C}$ for at least 4 days until the toothpick pieces were well-colonized with $R$. solani.

Inoculation method. Plants were maintained on benches in a greenhouse $\left(30^{\circ} \mathrm{C}\right.$ day; $22^{\circ} \mathrm{C}$ night). From November through March, metal halide lights provided supplemental lighting with an intensity of 240 to $300 \mu \mathrm{mol} \cdot \mathrm{m}^{-2} \cdot \mathrm{s}^{-1}$ at plant level for $9 \mathrm{~h}$ during the day. Inoculations were done at the beginning of the panicle exsertion growth stage or later. The growth stage was recorded. Only one isolate was used for a given pot with a particular cultivargermplasm. Over all replications, each cultivar-germplasm was inoculated with GRUBBS18A three times, 95KBNT three times, and LNG-14A two times.

Tillers were inoculated with colonized toothpicks placed in the leaf sheath at the collar, without wounding, in up to five leaves of a particular tiller. Immediately after inoculation, plants were covered with a plastic bag and incubated in the growth chamber at $14 \mathrm{~h} \mathrm{light} / 10 \mathrm{~h}$ dark, $28^{\circ} \mathrm{C}$, and 92 to $100 \%$ humidity for 1 week. At plant height, the light intensity in the growth chamber ranged from 750 to $950 \mu \mathrm{mol} \cdot \mathrm{m}^{-2}$. $\mathrm{s}^{-1}$, and under the bag, readings were decreased by $100 \mu \mathrm{mol} \cdot \mathrm{m}^{-2} \cdot \mathrm{s}^{-1}$. After 7 days, plants in a single pot were given one visual rating on a scale from 0 to 9 , where $0=$ no lesions present on the plants, $1=$ lesions covering $10 \%$ of the leaves, $2=20 \%$ of the leaves, $3=30 \%$ of the leaves, and so on, to $9=$ lesions covering all leaves (90 to $100 \%$ dead leaves) with significant panicle death. This rating method differed slightly from field rating systems that rely on the height of sheath blight symptoms in the plant (23). The growth stage of the individual rice plants was recorded when the plants were rated. The leaves were numbered 1 to 5 , with leaf 1 being the most mature leaf at the base of the tiller and leaf 5 being the flag leaf on the primary tiller (28). Some of the secondary tillers and most of the ratoon tillers, described below, only had four leaves; thus leaf 1 was the most mature leaf and leaf 4 the flag leaf. Sheath blight lesion length was measured down the leaf sheath and up the leaf blade, from the point of inoculation at the collar. These two measurements for each leaf were totaled to give the "lesion length" for each individual leaf of the tiller. Comparisons were made using the median lesion length for each individual leaf (leaf 1 to leaf 5) and for selected leaves totaled (leaves 1, 2, and 3; 1 and 2; 2 and 3; and 2, 3, and 4). The lesion length was not determined for senescent leaves.

After the primary-secondary tillers were evaluated, the tillers were cut off at about 7 $\mathrm{cm}$ (3 in) above the soil surface. Tillers, described as "ratoon tillers," began to emerge from the cut tillers about 2 to 3 weeks later. When the ratoon tillers were at the appropriate growth stage, the tillers were inoculated using the method described above. Differences from the primary-secondary tillers were (i) ratoon tillers had fewer leaves so at most four leaves were inoculated, and (ii) ratoon tillers of a particular cultivar-germplasm were inoculated four times with each isolate.

Experimental design and statistical evaluation. Statistical analysis of the cultivated rice data was made assuming the experimental design was a randomized complete block design. Two pots of each cultivar-germplasm with four plants per pot were included each time the experiment was repeated. The primarysecondary tillers were evaluated four times and the ratoon tillers six times.

Data analysis was done using SAS (Statistical Analysis Systems) procedures (22). The correlation between the means of the visual rating for sheath blight and the length of the disease lesions was determined using SAS procedures MEANS and CORR. The visual rating and mean separation were determined using SAS general linear models (GLM) procedure. The uniformity of the data was tested and the median lesion length determined using SAS procedure UNIVARIATE. Median length was reported to eliminate skewing from extremes in the data due to plants not being infected or other factors interfering with the rating.

Oryza species evaluation. Ratoon tillers of 21 Oryza spp. and $\mathrm{F}_{1}$ progeny of selected Oryza spp. crossed with either the medium grain cultivar, Bengal, or the long grain experimental line, RU9401188, were tested for sheath blight resistance according to the methods described above. Ratoon tillers were selected so that $F_{1}$ progeny could be confirmed by panicle morphology. The method was tested with the Oryza spp. two times. Each time, data were collected from two pots containing two to four plants per pot of the given Oryza sp. Due to limited $\mathrm{F}_{1}$ hybrids, the method was tested three times with the hybrids. Each time, there was one pot containing one to three plants of the given $F_{1}$ hybrid. Data for the hybrids were combined over cultivated parent. Data obtained from inoculation of the Oryza spp. and $\mathrm{F}_{1}$ hybrids were analyzed assuming that each time, the experiment was repeated as a replication and using the statistical procedures described above.

\section{RESULTS}

Disease development on primary and secondary cultivated rice tillers. In this study, plants were evaluated for sheath blight susceptibility when the earlier maturing cultivars (Cypress, LSBR-5, LSBR33, Maybelle) were in anthesis to the seed forming growth stages, which correspond to the rice reproductive growth stages, R4, R5, and R6 (5). Later maturing cultivars (Katy, Lacassine, Lebonnet, Leah, Mars) had panicles exserted to the shedding pollen, R3 to R5 growth stage, respectively. The growth stage during which the plants were inoculated was an important consideration when evaluating sheath blight resistance because sheath blight generally be- 
gan rapid development after the tillers started to elongate in the R2 growth stage. Sheath blight infection was not as severe if the plants were inoculated at the R2 growth stage or earlier.

Visual ratings for sheath blight resistance of the primary and secondary tillers (Table 1) generally corresponded to ratings previously obtained from field studies. An exception was LSBR-33, which rated 1 to 3 or resistant in reported field evaluations (27) but rated 4.8 and was more susceptible than Leah and Katy in our growth chamber trial (Table 1). Other cultivarsgermplasms rated the same or slightly more susceptible in the growth chamber tests than reported field ratings. Visual rating of the ratoon tillers for sheath blight infection (Table 1) was similar to the rating of the primary and secondary tillers in the growth chamber. Comparing these ratings, Katy rated more susceptible, 3.6 versus 4.8, whereas Lebonnet and Cypress, more susceptible lines, had lower ratings, 6.5 versus 5.3 and 6.9 versus 5.9, respectively, using ratoon tillers as compared to primary and secondary tillers. The analysis of variance determined the cultivar by isolate interaction was nonsignificant.

When the primary and secondary tillers of plants were measured, most symptom development occurred in the second and third leaves. Often the lowest leaf was senescent; thus the lesion could not be measured or the measurement was considered inaccurate. Correlation of the visual rating with the lesion length for the individual leaves (first, second, third, and fourth) and total lesion length for various combinations of leaves was determined. The best Pearson correlation coefficient, 0.98 at $P<0.0001$, was found by adding the lesion lengths of the second and third leaves. For comparison, the correlation of the visual rating with (i) the first, second, and third leaves mean lesion length total was 0.85 at $P=0.004$, (ii) the second leaf alone was 0.84 at $P=0.004$, and (iii) the first and second leaves were 0.58 at $P=$ 0.098 . The median lesion length is reported in Table 1 to eliminate skewing from the extremes in the data. From this analysis, the less susceptible cultivars had a median lesion length less than $11.0 \mathrm{~cm}$ for the second and third leaf total and less than $19.0 \mathrm{~cm}$ for the first, second, and third leaf total (Table 1). The more susceptible cultivars had a median lesion length greater than $11.0 \mathrm{~cm}$ for the second and third leaf total and greater than $20.0 \mathrm{~cm}$ for the first, second, and third leaf total (Table 1).

Disease development on ratoon cultivated rice tillers. For the ratoon tillers, sheath blight infection was more severe in the first and second leaves than in the third leaf. Ratoon tillers develop from primary or secondary tillers, and these tillers often had only three leaves before the panicle exserted. In contrast, most primarysecondary tillers had four or five leaves. Correlation of the visual rating with the lesion length for the individual ratoon tiller leaves (first, second, and third) and total lesion length of various combinations of leaves were determined. The Pearson correlation coefficient was the highest for the second leaf alone with 0.87 at $P=0.002$. For comparison, the second and third leaf total had a correlation of 0.80 at $P=0.009$, and the first and second leaf total a correlation of 0.76 at $P=0.02$. Table 1 shows the median lesion length for the less susceptible cultivars was less than $7.0 \mathrm{~cm}$ for the second and third leaf total, with the exception of Mars, which had a length of $7.4 \mathrm{~cm}$. The median lesion length for the less susceptible cultivars was less than $9.5 \mathrm{~cm}$ for the first and second leaf total and less than $4.5 \mathrm{~cm}$ for the second leaf alone. Maybelle was the only cultivar rated more susceptible in the growth chamber that had lesion measurements in the range of the less susceptible cultivars.

R. solani isolates. Analysis of the data according to $R$. solani isolates showed the $R$. solani isolates, GRUBB18A and LNG-
14A, caused significantly less severe infection compared with 95KBNT. In about half of the cases, there was a significant difference among all three isolates in the severity of infection, when the severity was determined by lesion length of the second leaf, first and second leaves, second and third leaves, and visual rating. Differences in virulence, the amount of infection caused by the $R$. solani isolates, were previously reported by Pascual et al. (20) in a study of $R$. solani isolates (anastomosis group AG1IA) causing banded leaf and sheath blight of maize (Zea mays L.). Isolate 95KBNT was used in most later Oryza spp. inoculations because of its more severe sheath blight infection.

Disease development on ratoon Oryza species tillers. Twenty-two of the Oryza spp. reported as sheath blight resistant (9) were evaluated using the growth chamber (Table 2). All but one of the 21 accessions visually rated less than 5 , considered moderately susceptible to resistant. All but six had a median lesion length of less than $13.0 \mathrm{~cm}$ for the second and third leaf total, these being $O$. meridionalis (17.7), $O$. officinalis (15.9), O. barthii (14.8), O. nivara/O. sativa (14.6), O. glumaepatula (14.4), and $O$. australiensis (13.7). The best Pearson correlation coefficients between the visual rating and lesion measurement were 0.49 at $P=0.025$ for the second and third leaf total and 0.65 at a $P$ $=0.0015$ for the second leaf alone. In general, the Oryza spp. rated as more resistant had lesion measurements of less than 15.0 $\mathrm{cm}$ for the first and second leaf total, less than $13.0 \mathrm{~cm}$ for the second and third leaf total, and less than $7.0 \mathrm{~cm}$ for the second leaf alone. Observed factors that made these correlations less accurate than for the ratoon tillers of the cultivated rice were more variation in plant type, i.e., variation in plant morphology such as height, leaf length, and leaf width; differences in days to maturity; and fewer replications. Oryza

Table 1. Summary of U.S. rice cultivars-germplasm evaluated for sheath blight resistance using a visual rating and measurement of the lesion length for the first, second, and third leaves in various combinations

\begin{tabular}{|c|c|c|c|c|c|c|c|}
\hline \multirow{3}{*}{$\begin{array}{l}\text { Cultivar- } \\
\text { Germplasm }\end{array}$} & \multicolumn{3}{|c|}{ Primary-secondary tillers ${ }^{a}$} & \multicolumn{4}{|c|}{ Ratoon tillers $^{\mathbf{a}}$} \\
\hline & \multirow[b]{2}{*}{ Visual rating ${ }^{\mathbf{b}}$} & \multicolumn{2}{|c|}{ Median lesion length $(\mathrm{cm})^{\mathrm{c}}$} & \multirow[b]{2}{*}{ Visual rating ${ }^{b}$} & \multicolumn{3}{|c|}{ Median lesion length $(\mathrm{cm})^{\mathrm{c}}$} \\
\hline & & Leaves $2+3$ & Leaves $1+2+3$ & & Leaves $2+3$ & Leaves $1+2$ & Leaf 2 \\
\hline Leah & 3.4 & 8.9 & 18.1 & 3.1 & 2.9 & 6.1 & 2.2 \\
\hline Katy & 3.6 & 7.7 & 13.1 & 4.8 & 6.1 & 8.6 & 3.7 \\
\hline Mars & 3.9 & 10.0 & 15.7 & 3.6 & 7.4 & 9.2 & 4.4 \\
\hline LSBR-5 & 4.0 & 10.7 & 18.3 & 3.3 & 4.4 & 7.5 & 2.1 \\
\hline LSBR-33 & 4.8 & 11.9 & 20.2 & 5.4 & 7.3 & 10.7 & 5.1 \\
\hline Lacassine & 5.1 & 13.2 & 22.6 & 5.6 & 7.8 & 10.0 & 5.5 \\
\hline Maybelle & 6.2 & 16.2 & 23.4 & 5.6 & 6.2 & 8.1 & 3.5 \\
\hline Lebonnet & 6.5 & 13.9 & 31.0 & 5.3 & 9.1 & 12.6 & 5.9 \\
\hline Cypress & 6.9 & 15.9 & 21.2 & 5.9 & 7.5 & 10.6 & 5.9 \\
\hline LSD (0.05) & 1.0 & 2.5 & 3.2 & 0.8 & 2.3 & 2.0 & 1.3 \\
\hline
\end{tabular}

${ }^{a}$ Data on the primary-secondary tillers include four replications and on the ratoon tillers six replications. Each replication included two pots of each cultivar-germplasm with four plants per pot.

${ }^{\mathrm{b}}$ Mean of visual ratings based on a scale of $0=$ no lesions to $9=$ lesions covering all leaves and panicles.

${ }^{c}$ Median of the total lesion length for the first (1), second (2), and/or third (3) leaves as described in the column heading. Lesions were measured from the collar down the leaf sheath and from the collar up the leaf blade for each leaf. The first leaf is the most mature and closest to the ground. 
spp. ratings were based on four pots compared with the cultivated rice tests, which had four replications of the primarysecondary tillers and six replications of the ratoon tillers with each replication having two pots.

The $O$. sativa parents, Bengal and RU9401188, used in crosses with the Oryza spp. were evaluated using this method (Table 2). Both parents were rated as moderately susceptible, with Bengal having slightly longer lesion lengths. These ratings corresponded to moderately susceptible field ratings for sheath blight (24; K. A. K. Moldenhauer, University of Arkansas, personal communication).

Disease development on ratoon tillers of $\mathrm{F}_{1}$ hybrids (cultivated rice/Oryza $\mathrm{sp}$.). The $\mathrm{F}_{1}$ hybrids between cultivated rice and 17 of the Oryza spp. listed in Table 2 were rated for sheath blight resistance (Table 3). Because ratings of the cultivated parents used in this study were similar (5.7 and 6.0 in Table 2) and the objective was to evaluate the Oryza sp., ratings in Table 3 were combined (i) for hybrids with Bengal and RU9401188 by Oryza sp. and (ii) for the cultivated parents the data were summarized over all Oryza spp. Exceptions were $O$. barthii (IRGC 105609) and O. glumaepatula (IRGC 100924), which were crossed only with RU9401188. O. nivara/O. sativa (IRGC 100200) and $O$. officinalis (IRGC 101399) were crossed only with Bengal. The remaining 13 Oryza spp. were crossed with both parents.

The mean visual rating for hybrids with one parent being RU9401188 was negligibly less than the corresponding mean for those hybrids with Bengal as a parent, 5.0 versus 5.1, respectively (Table 3 ). This slight difference, Bengal rating higher than RU9401188, corresponded to the difference observed in growth chamber and field ratings of these two cultivated parents. When compared with the visual ratings of the Oryza spp. parents, the $F_{1}$ hybrids from crosses with the moderately susceptible cultivated parents had higher ratings.

Median lesion lengths of most $F_{1}$ hybrids were less than $11.5 \mathrm{~cm}$ for the first and second leaf total, less than $7.0 \mathrm{~cm}$ for the second and third leaf total, and less than $4.5 \mathrm{~cm}$ for the second leaf alone. These lesion lengths were similar to those observed for the ratoon tillers of the less susceptible cultivated rice (Table 1) for the second and third leaf total, and second leaf alone, and were due to the $\mathrm{F}_{1}$ hybrid plant type being more like the cultivated parent. The best correlation was 0.55 at $P=$ 0.0015 between the visual rating and the mean for the individual $F_{1}$ hybrid lesion length of first and second leaf total. The correlation of the visual rating with the lesion length of the second leaf alone was 0.51 at $P=0.004$, and correlation of the second and third leaf total was only 0.29 at $P=0.12$.
Table 2. Summary of the Oryza species evaluated for sheath blight resistance on ratoon tillers using a visual rating and median value of the total lesion length for first, second, and third leaves in various combinations ${ }^{\mathrm{a}}$

\begin{tabular}{|c|c|c|c|c|c|}
\hline \multirow{2}{*}{$\begin{array}{l}\text { Oryza species } \\
\text { or cultivar }\end{array}$} & \multirow[b]{2}{*}{ IRGC no. } & \multirow{2}{*}{$\begin{array}{l}\text { Visual } \\
\text { rating }\end{array}$} & \multicolumn{3}{|c|}{ Median lesion length $(\mathrm{cm})^{c}$} \\
\hline & & & Leaves 1+2 & Leaves $2+3$ & Leaf 2 \\
\hline O. rufipogon & 100912 & 2.3 & 8.9 & 9.7 & 2.2 \\
\hline O. nivara & 105316 & 2.8 & 13.5 & 7.0 & 4.9 \\
\hline O. barthii & 105609 & 3.0 & 6.7 & 5.6 & 0.1 \\
\hline O. nivara/O. sativa & 100943 & 3.2 & 27.4 & 14.6 & 11.4 \\
\hline O. barthii & 104286 & 3.3 & 1.6 & 2.2 & 1.9 \\
\hline O. meridionalis & 105306 & 3.3 & 13.7 & 7.4 & 5.8 \\
\hline O. glumaepatula & 100924 & 3.4 & 21.4 & 11.6 & 6.6 \\
\hline O. officinalis & 101399 & 3.5 & 13.2 & 4.3 & 4.2 \\
\hline O. nivara/O. sativa & 100200 & 3.8 & 11.6 & 8.7 & 0.6 \\
\hline O. sativa/O. nivara & 100606 & 3.8 & 13.7 & 8.1 & 6.9 \\
\hline O. latifolia & 100169 & 3.8 & 8.5 & 12.2 & 6.3 \\
\hline O. nivara & 100898 & 4.0 & 14.2 & 3.0 & 2.1 \\
\hline O. nivara & 100593 & 4.0 & 15.3 & 5.4 & 4.4 \\
\hline O. meridionalis & 105300 & 4.0 & 14.3 & 17.7 & 3.0 \\
\hline O. glumaepatula & 105670 & 4.3 & 19.2 & 7.5 & 5.7 \\
\hline O. meridionalis & 103317 & 4.4 & 18.5 & 9.1 & 6.9 \\
\hline O. australiensis & 103318 & 4.5 & 17.3 & 13.7 & 5.9 \\
\hline O. barthii & 100935 & 4.5 & 18.7 & 14.8 & 7.7 \\
\hline O. glumaepatula & 105465 & 4.7 & 21.6 & 14.4 & 6.1 \\
\hline O. nivara & 104705 & 4.8 & 22.4 & 7.0 & 7.0 \\
\hline O. officinalis & 105394 & 7.0 & 18.8 & 15.9 & 12.7 \\
\hline Bengal & Medium grain & 6.0 & 18.5 & 14.0 & 8.1 \\
\hline RU9401188 & Long grain & 5.7 & 11.4 & 7.0 & 5.6 \\
\hline LSD (0.05) & & 2.2 & 7.8 & 11.7 & 4.8 \\
\hline
\end{tabular}

a Bengal and RU9401188 are $O$. sativa developed by southern U.S. breeding programs.

${ }^{\mathrm{b}}$ Mean of visual ratings for plants in individual pots where $0=$ no lesions present on the plants and 9 $=$ lesions covering all leaves and panicles. Ratings were averaged over two different times, each of which included two pots with two to four plants per pot.

${ }^{\mathrm{c}}$ Median of the total lesion length for the first (1), second (2), and/or third (3) leaves as described in the column heading. The lesions were measured from the collar down the leaf sheath and from the collar up the leaf blade for each leaf. The first leaf is the most mature and closest to the ground.

Table 3. Sheath blight resistance in ratoon $\mathrm{F}_{1}$ plants (cultivated rice crossed with Oryza sp.) evaluated using a visual rating and median from measuring the lesion length of the first, second, and third leaves in various combinations

\begin{tabular}{|c|c|c|c|c|c|}
\hline \multirow[b]{2}{*}{$\mathrm{F}_{1}$ Oryza species } & \multirow[b]{2}{*}{ IRGC no. } & \multirow{2}{*}{$\begin{array}{l}\text { Visual } \\
\text { ratinga }\end{array}$} & \multicolumn{3}{|c|}{ Median lesion length $(\mathrm{cm})^{b}$} \\
\hline & & & Leaves 1+2 & Leaves $2+3$ & Leaf 2 \\
\hline O. barthii & 104286 & 3.5 & 7.4 & 6.9 & 3.9 \\
\hline O. officinalis & 101399 & 4.0 & 10.2 & 7.6 & 4.0 \\
\hline O. nivara/O. sativa & 100200 & 4.3 & 9.7 & 6.1 & 5.4 \\
\hline O. nivara/O. sativa & 100943 & 4.4 & 9.4 & 5.2 & 3.2 \\
\hline O. glumaepatula & 100924 & 4.6 & 6.7 & 2.7 & 1.6 \\
\hline O. sativa/O. nivara & 100606 & 4.7 & 10.2 & 5.9 & 3.2 \\
\hline O. rufipogon & 100912 & 4.8 & 7.7 & 2.6 & 2.3 \\
\hline O. glumaepatula & 105465 & 5.0 & 9.1 & 6.9 & 3.1 \\
\hline O. nivara & 104705 & 5.2 & 8.7 & 4.8 & 3.3 \\
\hline O. nivara & 100898 & 5.2 & 11.3 & 4.2 & 3.7 \\
\hline O. meridionalis & 105300 & 5.2 & 11.1 & 6.8 & 5.3 \\
\hline O. barthii & 100935 & 5.2 & 10.8 & 10.9 & 5.2 \\
\hline O. meridionalis & 103317 & 5.3 & 10.9 & 6.7 & 3.7 \\
\hline O. nivara & 105316 & 5.5 & 11.6 & 5.3 & 5.0 \\
\hline O. nivara & 100593 & 5.5 & 12.0 & 7.0 & 6.2 \\
\hline O. meridionalis & 105306 & 6.0 & 10.8 & 6.1 & 4.9 \\
\hline O. barthii & 105609 & 6.5 & 12.1 & 9.7 & 7.9 \\
\hline Bengal & Medium grain & 5.1 & 9.2 & 5.5 & 3.6 \\
\hline RU9401188 & Long grain & 5.0 & 10.3 & 6.7 & 4.0 \\
\hline LSD (0.05) & & 1.5 & 3.2 & 3.1 & 2.0 \\
\hline
\end{tabular}

a Mean of visual ratings for plants in individual pots where $0=$ no lesions present on the plants and 9 $=$ lesions covering all leaves and panicles. Ratings were averaged over female parent (Bengal or RU9401188) for Oryza sp. or male parent (Oryza spp.) for Bengal and RU9401188, and over three different times, each of which included one pot of each available cross with one to three plants per pot.

b Median of the total lesion length for the first (1), second (2), and/or third (3) leaves as described in the column heading. The lesions were measured from the collar down the leaf sheath and from the collar up the leaf blade for each leaf. The first leaf is the most mature and closest to the ground. 


\section{DISCUSSION}

This study demonstrated that ratoon plants of various Oryza spp. could be accurately evaluated for sheath blight resistance in a greenhouse-growth chamber environment by rating the plants visually and measuring disease lesion length. Measurements of the lesions on the first, second, and third leaves were the most useful in determining the severity of the sheath blight infection on individual plants. In the case of a primary or secondary tiller, an overall rating and the lesion lengths on the second and third leaves were more reliable. For the ratoon tillers of Oryza spp., the measurement of the lesion on the second leaf was the most useful. This is because the ratoon tillers are smaller and often the first leaf is not present. Depending on the Oryza sp. being evaluated, the combination with the first or third leaf lesion length also was helpful in verifying the amount of disease infection. The method of measuring lesion length and giving a visual rating was easier and faster than the method of counting the number of infection cushions as reported by Groth and Nowick (7). They also concluded that visual ratings described as "mean lesion type" in greenhouse evaluations and "disease reaction" in field evaluations were better correlated and less tedious and time-consuming than counting infection cushions in the infected leaf sheath as part of the greenhouse evaluation.

Savary and Mew (23) summarized three different approaches for assessing sheath blight resistance as (i) developing formulas for categories of disease intensity, (ii) measuring the disease progress in the canopy, and (iii) evaluating the disease intensity for the whole plot. The most widely used system is a combination of the first two approaches, using a 9-point scale which breaks the progression of the disease into categories (23). Our data present a disease intensity approach based on an overall rating, measurement of the lesion length and leaf position for use in a growth chamber with Oryza spp. To account for variation in leaf length among Oryza spp., the total length of the leaf should be measured so that the relative lesion length can be calculated. (Leaf length data were not collected in this study.)

As noted earlier, it is important to consider the source of sheath blight isolates because of differences in the isolate virulence, in other words, severity of sheath blight infection. Observed differences in isolate virulence may in part be due to GRUBB18A and LNG-14A being collected from diseased fields much earlier (early 1980s) than 95KBNT (1995). It is possible the isolates have changed in virulence due to continuous storage and culture in the laboratory. This underscores the importance of using more than one isolate to develop a better understanding of the individual isolate's virulence and character of pest resistance. In the future, more accurate methods to determine the phylogenetic relationships between the sheath blight isolates using DNA markers (10) may assist in determining the genetic variation in the existing population of sheath blight isolates.

In summary, this technique uses growth chamber data from primary and secondary tillers and/or ratoon tillers to reliably evaluate sheath blight resistance in Oryza spp. and other diverse plant types that cannot be evaluated under field conditions. This method is useful for the initial sheath blight screening of Oryza spp. and early generation progenies that shatter seed. More selective screening should be conducted in the field after the shattering character has been eliminated in subsequent backcross generations.

\section{ACKNOWLEDGMENTS}

The authors gratefully acknowledge the excellent technical assistance of Betty A. Novak and the expertise of H. Del Var Petersen with the statistical analyses. Leno Robinson and Casey Condra assisted with this research through the support of the USDA-ARS Summer Internship Program for college students.

\section{LITERATURE CITED}

1. Amante-Bordeos, A., Sitch, L. A., Nelson, R., Dalmacio, R. D., Oliva, N. P., Aswidinnoor, H., and Leung, H. 1992. Transfer of bacterial blight and blast resistance from the tetraploid wild rice Oryza minuta to cultivated rice, Oryza sativa. Theor. Appl. Genet. 84:345-354.

2. Bollich, C. N., Webb, B. D., Marchetti, M. A., and Scott, J. E. 1991. Registration of 'Maybelle' rice. Crop Sci. 31:1090.

3. Bollich, C. N., Webb, B. D., Scott, J. E., and Atkins, J. G. 1975. Registration of 'Lebonnet' rice. Crop Sci. 15:886.

4. Carling, D. E. 1996. Grouping in Rhizoctonia solani by hyphal anastomosis reaction. Pages 37-47 in: Rhizoctonia Species: Taxonomy, Molecular Biology, Ecology, Pathology and Disease Control. B. Sneh, S. Jabajihare, S. Neate, and G. Dijst, eds. Kluwer Academic Publisher, Dordrecht, Netherlands.

5. Counce, P. A., Keisling, T. C., and Mitchell, A. J. 2000. A uniform, objective, and adaptive system for expressing rice development. Crop Sci. 40:436-443.

6. Figoni, R. A., Rutger, J. N., and Webster, R. K. 1983. Evaluation of wild Oryza species for stem rot (Sclerotium oryzae) resistance. Plant Dis. 67:998-1000.

7. Groth, D. E., and Nowick, E. M. 1992. Selection for resistance to rice sheath blight through number of infection cushions and lesion type. Plant Dis. 76:721-723.

8. Hashiba, T. 1984. Estimating method of severity and yield loss by rice sheath blight disease. Bull. Hokuriku Nat. Agric. Exp. Stn. 26:115-164.

9. International Rice Research Institute. 1992. Resistance of conserved germplasm to nonspecialized pathogens. Pages 140-143 in: IRRI Program Report for 1992.

10. Jia, Y., Singh, P., Wang, Z., Cartwright, R., Lee, F. N., and Eizenga, G. C. 2002. Cytological and molecular characterization of the rice sheath blight pathogen, Rhizoctonia solani. Proc. Rice Tech. Working Group, 29th. In press.

11. Johnston, T. H., Wells, B. R., Marchetti, M.
A., Lee, F. N., and Henry, S. E. 1979. Registration of 'Mars' rice. Crop Sci. 19:743.

12. Lakshmanan, P. 1991. Resistance to sheath blight (ShB) and brown spot (BS) in lines derived from Oryza officinalis. Int. Rice Res. Newsl. 16(6):8.

13. Lee, F. N., and Rush, M. C. 1983. Rice sheath blight: A major rice disease. Plant Dis. 67:829-832.

14. Li, Z. K., Pinson, S. R., Marchetti, M. A., Stansel, J. W., and Park, W. D. 1995. Characterization of quantitative trait loci (QTLs) in cultivated rice contributing to field resistance to sheath blight (Rhizoctonia solani). Theor. Appl. Genet. 91:382-388.

15. Linscombe, S. D., Jodari, F., McKenzie, D. S., Bollich, P. K., Groth, D. E., and White, L. M. 1992. Registration of 'Lacassine' rice. Crop Sci. 32:494.

16. Linscombe, S. D., Jodari, F., McKenzie, K. S., Bollich, P. K., White, L. M., Groth, D. E., and Dunand, R. T. 1993. Registration of 'Cypress' rice. Crop Sci. 33:355.

17. Linscombe, S. D., Jodari, F., McKenzie, K. S., Bollich, P. K., White, L. M., Groth, D. E., and Dunand, R. T. 1993. Registration of 'Bengal' rice. Crop Sci. 33:645-646.

18. Moldenhauer, K. A. K., Lee, F. N., Norman, R. J., Helms, R. S., Wells, B. R., Dilday, F. H., Rohman, P. C., and Marchetti, M. A. 1990. Registration of 'Katy' rice. Crop Sci. 30:747748.

19. Pan, X. B., Rush, M. C., Sha, X. Y., Xie, Q. J., Linscombe, S. D., Stetina, S. R., and Oard, J. H. 1999. Major gene, nonallelic sheath blight resistance from the rice cultivars 'Jasmine 85' and 'Tequing'. Crop Sci. 39:338-346.

20. Pascual, C. B., Toda, T., Raymondo, A. D., and Hyakumachi, M. 2000. Characterization by conventional techniques and PCR of Rhizoctonia solani isolates causing banded leaf sheath blight in maize. Plant Pathol. 49:108-118.

21. Rush, M. C., and Lee, F. N. 1992. Sheath blight. Pages 22-23 in: Compendium of Rice Diseases. R. K. Webster and P. S. Gunnell, eds. American Phytopathological Society, St. Paul, MN.

22. SAS Institute. 1998. The SAS System for Windows. Release 7.00. SAS Institute, Cary, NC.

23. Savary, S., and Mew, T. W. 1996. Analyzing crop losses due to Rhizoctonia solani: Rice sheath blight, a case study. Pages 237-245 in Rhizoctonia Species: Taxonomy, Molecular Biology, Ecology, Pathology and Disease Control. B. Sneh, S. Jabajihare, S. Neate, and G. Dijst, eds. Kluwer Academic Publisher, Dordrecht, Netherlands.

24. Slaton, N., Moldenhauer, K., Gibbons, J. Blocker, M., Bernhardt, J., Cartwright, R., Lee, F., Dilday, R., Robinson, J., Koen, B., and Black, H. 1999. Arkansas rice performance trials, 1997-1999. Rep. No. 143. University of Arkansas, Coop. Ext. Serv., Little Rock.

25. Trahan, G. J., Jodon, N. E., McIlrath, W. O., Sonnier, E. A., and McKenzie, K. S. 1982 Registration of 'Leah' rice. Crop Sci. 22:1086-1087.

26. Vaughn, D. A. 1994. The wild relatives of rice: A genetic resource handbook. International Rice Research Institute, Los Baños, Philippines.

27. Xie, Q. J., Linscombe, S. D., Rush, M. D., and Jodari-Karimi, J. 1992. Registration of 'LSBR-33' and 'LSBR-5' sheath blightresistant germplasm lines of rice. Crop Sci. 32:507.

28. Yoshida, S. 1981. Fundamentals of rice crop science. International Rice Research Institute, Los Baños, Philippines. 